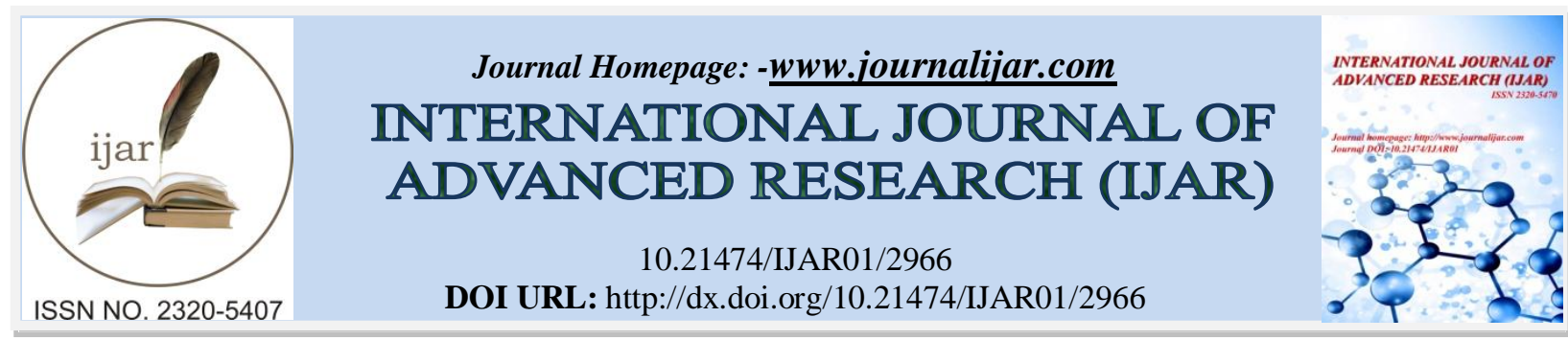

RESEARCH ARTICLE

\title{
TO STUDY THE NECESSITY AND SPECIAL TECHNIQUES USED FOR FORT REHABILITATION.
}

Harshal R. Jadhav and Abhijit A.Warudkar.

1. Post Graduate Student, Department of Civil Engineering, ICOER, PUNE.

2. Asst.Professor ,Department of Civil Engineering, ICOER, PUNE.

\section{Manuscript Info}

Manuscript History

Received: 30 November 2016

Final Accepted: 26 December 2016

Published: January 2017

Key words:-

Types of fort, Causes of deterioration

fort, Special Technique.

\section{Abstract}

This Paper discuss about need of fort rehabilitation and techniques used for fort rehabilitation. In order to pass on to future generations what is currently identified as being of cultural significance today, we must imbibe good conservation practices especially for the heritage buildings in order to prevent them from deterioration and extend the life and basic functions of these buildings. Heritage buildings were constructed in the past that have high historical, architectural, spiritual, social, political and economical values. Similarly heritage buildings are highly valuable and informative in terms of socio-cultural, socio-political, socio-economical and even technological activities of a specific society or group of individual. we need to prevent deterioration of fort and use the special techniques for fort rehabilitation

Copy Right, IJAR, 2016,. All rights reserved.

\section{Introduction:-}

Forts have been created for thousands of years and they are often the most durable and famous symbols of ancient civilizations. These are the icons of the nation having their own cultural and historic values therefore, it is very essential to conserve them .Forts which have no further utilization tend to decay rapidly, while which are still in use have a better chance of being maintained. Rehabilitation involves contribution of high end technology, advanced skills and calculations. This is a very responsible job of saving hazardous failure of structures due to deterioration. The success in rehabilitating the structure totally depends on gaining expertise in the field and day to day advancements. Rehabilitation is highly recommended for age-old buildings showing signs of decay and save human lives from failures.

\section{Types of fort:-}

Traditionally the Forts in Maharashtra were of the following types:

\section{Hill Forts:-}

The hill forts were constructed from stones carved out from the very mountains and joined with the help of lime, rubble, gravel, stones, bricks, molten metal and sand. Lime mortar was ground on the fort itself with the help of a roller passing though a circular channel. The stones formed the outer layer of the fort. Stone layers were often sandwiched between earth, rubble and mortar. At several places the stones appear joint in the male female format devoid of any use of mortar. The stones were joined by mortar. There were even instances of molten metal used to fill up fissures and strengthen the construction. Together they gave a construction that's lasted for centuries. 


\section{Land Fort:-}

These forts were created on the plains. In Marathi they were called Bhuikot. e.g Chakan fort, Bahadurgad, Solapur fort, Ahmednagar fort etc

\section{Sea Fort:-}

These forts were created in the middle of the sea at a shallow point with a solid foundation base and protected by its vicious waves. In Marathi they were called 'JalDurg'. Ch. Shivaji was quick to realize the importance of sea forts. They provided a efficient base for controlling sea traffic and trade. e.g Janjeera, Sindhudurg, Padmadurg, Khanderi , Underi etc.

\section{Forest Fort:-}

These forts were created amidst a dense jungle, protected by the trees, the reptiles and wild animals. They were the 'Vana Durg'. e.g Javali.

\section{Human Fort;-}

Human war formations, encampments often resembled forts. These were the 'Nar Durg'. Barring the last which is a type of a field fortification.

\section{Causes of Deterioration of Fort; - Natural Factors:- \\ Floods:-}

Floods can cause massive damage where forts are being destroyed by nature's water pressure. Though some might dry out, yet the moisture remaining within the floors, walls and roof may cause serious mold problems that will eventually wear the building away and create health dangers.

\section{Biological Factors:-}

Biological agencies such as mosses, fungus, algae, and insects affect construction materials like timber, bricks, stucco etc. Biological agencies attack generally wet timber that has over $20 \%$ moisture contents. Wet timber decomposes in damp condition, and once germination occurred it enters cracks and spreads fast making the timber to loose cellulose, thereby loosing its strength and shape which results in cracks, shrinkages and loose fittings.

\section{Moisture:-}

Moisture is regarded as a key agent causing gradual deterioration of Fort. It can be in solid, liquid or vapor form and it is always present in the atmosphere. When the surface temperature falls, condensation occurs and this can cause severe damages to heritage buildings.

\section{Ground salts and water:-}

Soluble salts are a principal agent of decay in porous building materials and a source of great frustration to those involved in the conservation of historic buildings. The behavior of salts may seem unpredictable since they can remain dormant for long periods and then suddenly become active causing damage and disfiguring historic fabric. In other cases the action of salts is progressive, weakening surfaces on a microscopic level over decades and centuries, causing natural erosion of the kind that would occur to stone in a quarry face. Weathering of Natural Building Stones and his description remains the most comprehensive source on the subject, outlining all the essential facts, the salts typically found and the mechanisms of crystallization and decay. Ground water table and salinity i.e. higher salt loads on building materials, for example due to capillary rising damp from the soil. The higher salt load may lead to faster decay of heritage building materials.

- Both increasing and decreasing ground water tables.

- Increasing salt concentration in ground water.

\section{Windstorm:-}

Wind primarily causes loading and mechanical damage to structures and materials. Windstorm damaged roofs was quiet often recorded in the past at is still as a major threat to historical structures. Most of the damage caused by the strong winds concerned the roof covering. Wooden shingles were much more resistant than for example ceramic of slate tiles. 


\section{Social Factors:- \\ Fire}

Fire has long been enemy of heritage buildings. Uncontrolled fire can cause an entire destruction of heritage buildings and its contents in only a few hours and its major effect is the potential loss of authenticity. Although the destroyed parts of the buildings can be replicated, the loss of the original historic fabric takes away from the building the cultural significance which makes it unique and important.

\section{Urban Development:-}

Large urban scale development has continued to threaten the existence of heritage buildings in the region for a long time. Many heritage buildings are being demolished to pave way for the construction of wider roads, schools, hospitals, shopping malls and parking. Some of these buildings, especially those located in the central business district, have been under threats of demolition from the public and private developers seeking more lucrative ventures only.

\section{Vandalism:-}

It is the behavior attributed originally to the Vandals, in respect of culture: ruthless destruction or spoiling of anything beautiful or venerable. The term also includes criminal damage such as graffiti and defacement directed towards any property without permission of the owner.

\section{Literature Review:-}

During last few decades lot of research has been carried out to discuss the special techniques for rehabilitation of fort. In this chapter the research work carried out by various by researchers on Rehabilitation of fort for better understanding of the present work.

\section{Necessity of Rehabilitation:-}

In this paper for the rehabilitation of any heritage structure or monument, first of all the grade of the building should be taken into account. Depending upon the grade of that structure, the rehabilitation program should be planned with the permission of Heritage Conservation Committee. Secondly, engineers should be aware of the materials available in the market. Engineers should select proper material and technique for the rehabilitation of the particular monument so that its aesthetic look is not changed. Properties of the old materials and new should match each other. All conditions of using the new materials should be suitable. For strengthening of members materials like FRP can be useful rather using jacketing of the members. Epoxy can be used for better strengthening instead of using cementations grout. While using these materials or techniques, compatibility of the new materials with old materials should be checked properly. And a periodic maintenance should be adopted. (Mulani and Kumthekar, 2015).

Egypt with its long distinctive history as the oldest civilization of the world and has hosted most of other civilizations; has a unique historical patrimony of buildings and sites that are considered a world heritage and need to be conserved. However, with the huge amount of these historical building and sites, which need substantial investments for conservation, the problem of prioritization comes on the surface. Rehabilitation and conservation strategies should aim to avoid the idea of static preservation, and not attempt to fossilize the past and convert it into a sort of open-air museum. Therefore, there is an urgent need for rehabilitation approaches which, maintain and sustain the essential qualities of the historical areas in old cities and of the life of the resident communities, but which can also adapt these physical structures and organic approach of revitalization is needed. Adaptation of form and function can proceed, however, within a stable matrix of building and urban patterns. Selectivity is crucial. This implies, for example, a choice of new design concepts and relevant new technologies to enable older buildings and areas to adapt successfully to modern needs but without destroying existing urban form.(Ayman and Nour, 1964).

The existing buildings nearing its serviceability life and showing sign of breakdown does calls for technical intervention for enhancing their life and to avoid any accidental failure due to seismic event or other structural reason. The deterioration of the structures takes place due to weathering action, Fire, Natural calamities like earthquake, Flood, Tsunami, cyclones, Soil and structure interaction, defects in construction and many more. Post the technical evaluation of such structures, the decision to repair or replace a structure or its component has to be taken. This has to be in compliance with economy, construction feasibility and as per latest trends and techniques. The approach towards rehabilitation of any building can be categorized in following steps and actions. Evaluating various retrofitting options, materials, feasibility and economy, Performing structural calculations and capacity 
demand ratio for structural members, Suggesting retrofitting/construction system and getting the rehabilitation of the building done, Post retrofitting tests on the building.(Chandar, 2014)

In this paper it is discussed that India has a very rich historic background which is evident from various buildings, forts, temples, landscapes, objects of historic era. Many of these were constructed several hundred years ago when the Indian Civilization was at its peak. Their architecture, design and construction at the time when computers, code of practice, design guidelines, research institutions and modern construction techniques did not exist makes one to realize the wisdom and expertise of our forefathers. These structures have managed to survive for hundreds of years while most of the modern constructions need repair after couple of years of service. Physical materials of an earlier time, that might have been state of the art at the time of construction, might have failed and now need replacement with contemporary better functioning, but aesthetically similar materials. Such reasons make it mandatory to instigate a systematic approach in the area of heritage conservation. Deterioration of the structure may be caused due to various reasons, some of which are long life, lack of maintenance, unchecked growth of trees and creepers on the structures, improper drainage system, irregular inspection, material deterioration and weathering effect etc. Also, modern codes and building standards, observance of cultural context, conservation criteria, attainable benefit, traditional and innovative methods etc. pose major challenges in restoration of heritage structure. The best therapy to reduce decay is preventive maintenance. Adequate maintenance can limit or postpone the need for subsequent intervention. The choice between "traditional" and "innovative" techniques should be weighed up on a case-by-case basis and preference given to those that are least invasive and most compatible with heritage values, bearing in mind safety and durability requirements. The removal or alteration of any historic material or distinctive architectural features should be avoided whenever possible. Deteriorated structures whenever possible should be repaired rather than replaced.(Sandbhor and Botre, 2013)

\section{Methodology:-}

For carrying out the proposed work, following methodology will be adopted for data collecting and analysis.

1. Collection of relevant research data from national and international journals, web source etc.

2. Physically visiting the forts $\&$ collecting information.

3. Interviewing the personal associated with rehabilitation.

Interviewing the personal associated with the archeological department to study the feasibility the various materials recently developed in market

\section{Techniques Used In Fort Rehabilitation:-}

There are new materials and techniques which can be used for rehabilitation work .By this new technique the work can be done in a perfect way. Some of the techniques and material are as follows:

1. Epoxy injection

2. Gunite or Shotcrete

3. Mortar repair for cracks

4. Foamed concrete

5. Mortar and dry pack

6. Vacuum Concrete

7. Shoring and underpinning

8. Repointing

9. Grouting Techniques

\section{Epoxy injection:-}

Resin injection is based to repair concrete that is cracked or delaminated and to seal cracks in concrete to water leakage. Two basic types of resin and injection techniques are used to repair concrete; epoxy resins and polyurethane resins. Epoxy resins cure to form solids with high strength and relatively high module of elasticity. These materials bond readily to concrete and are capable, when properly applied, of restoring the original structural strength to cracked concrete. The high modules of elasticity causes epoxy resin systems to be unsuitable for rebonding cracked concrete that will undergo subsequent movement. The epoxies, however, do not cure very quickly, particularly at low temperatures, and using them to stop large flows of water may not be practical. Cracks to be injected with epoxy resins should be between 0.005 inch and 0.25 inch in width. It is difficult or impossible to inject resin into cracks less than 0.005 inch in width, while it is very difficult to retain injected epoxy resin in cracks greater than 0.25 inch in width, although high viscosity epoxies have been used with some success Epoxy resins 
cure to form relatively brittle materials with bond strengths exceeding the shear or tensile strength of the concrete. If these materials are used to rebound cracked concrete that is subsequently exposed to loads exceeding the tensile or shear strength of the concrete, if should be accepted that the cracks will recur adjacent to the epoxy bond line. In other words, epoxy resin should not be used to rebond "working" cracks. Epoxy resins will bond with varying degrees of success to wet concrete, and there are a number of special techniques that have been developed and used to rebond and seal water leaking cracks with epoxy resins. These special techniques and procedures are highly technical and, in most cases, are proprietary in nature. Polyurethane resins are used to seal and eliminate or reduce water leakage from concrete cracks and joints. They can also be injected into cracks that experience some small degree of movement. Such systems, with the exception of the two-part solid polyurethanes, have relatively low strengths and should not be used to structurally rebond cracked concrete. Cracks to be injected with polyurethane resin should not be less than 0.005 inch in width. No upper limit on crack width has been established for the polyurethane resins at the time this is being written. Polyurethane resins are available with substantial variation in their physical properties. Some of the polyurethanes cure into flexible foams. Other polyurethane systems cure to semi-flexible, high-density solids that can be used to rebond concrete cracks subject to movement. Most of the foaming polyurethane resins require some form of water to initiate the curing reaction and are, thus, a natural selection for use in repairing concrete exposed to water or in wet environments. At the time this is written, there are no standard specifications for polyurethane resins equivalent to the standard specification for Epoxy-Resin-Base Bonding Systems for Concrete.

The injections in cracks, internal or at the face, of a masonry wall are a solution of strengthening that is irreversible. They are, however, used frequently because, they preserve the original aspect of the exterior of the wall. It is particularly indicated for the rehabilitation of the masonry that has internal cracks connected between them. For this solution a cementicious based grout is used or a hydraulic based grout or others such as organic resins based grout. This solution is based on the injection in holes previously made with injection tubes and spread throughout the wall, to fill with the grout the internal cracks. For the external Cracks the coating should be removed previously and the Injection tubes may be used the aggregate grading of the grout depends on the size of the cracks but it can be used a grout without the sand. This technique shows improvements in the mechanical characteristics of the masonry. It seems a better application in stone masonry. To deliver a specific injection grout one must carry on in-situ and laboratory tests to refine the grout. Depending on the used process, there are several solutions for the injections. The process of Epoxy injection is shown in figure 8.1.

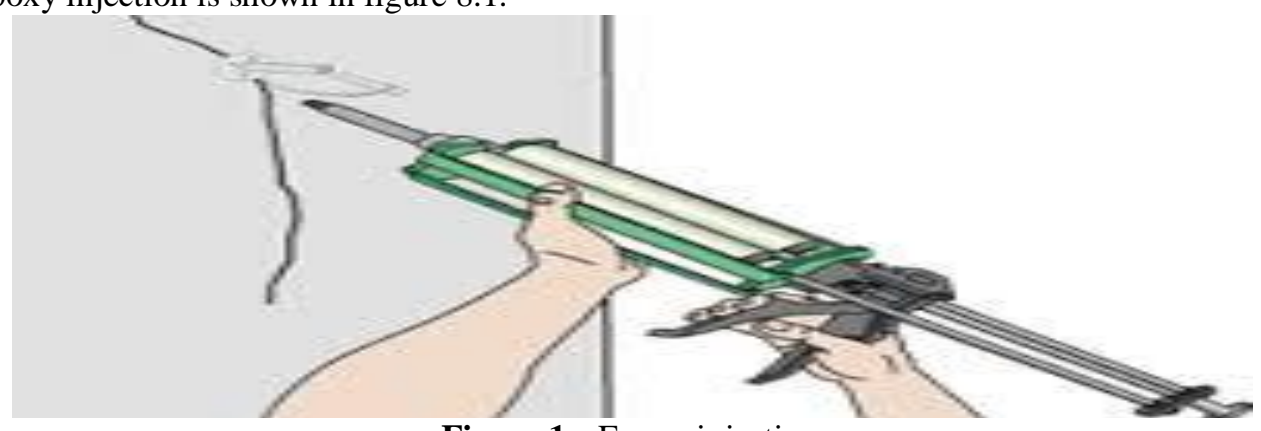

Figure 1:- Epoxy injection

1. Injection under pressure: It is frequently used in masonry. To avoid Structural failure of the wall, the holes are done from bottom to top and from side to centre.

2. Injection trough gravity: It is used to highly damaged walls.

Injection trough vacuum: It is used in small interventions, mainly architectural, statues, etc. The grout is very fluid for instance resins can be used. In old structures, the inorganic grouts, non cimenticious, like hydraulic lime, should be preferred because of compatibility issues with the already existing mortars . The organic mortars (polyester or epoxy), more fluid, should only be used when there are needs for higher resistance, hopefully without

\section{Gunite or Shotcrete:-}

Gunite can be defined as mortar conveyed through a hose and pneumatically projected at a high velocity on to a surface. Recently the method has been further developed by the introduction of small sized coarse aggregate into the mix deposited to obtain considerably greater thickness in one operation and also to make the process economical by reducing the cement content. Normally fresh material with zero slumps can support itself without sagging or peeling 
off. Sometimes use of set accelerators to assist overhead placing is practiced. The newly developed 'Ready set cement" can also be used for shotcreting process. There is not much difference guniting and shotcreting. Gunite was first used in the early 1900 and this process is mostly used of pneumatically application of mortar of less thickness, whereas shotcrete is a recent development on the similar principal of guniting for achieving greater thickness with small coarse aggregates. There are two different processes in use, namely the "Wet-mix" process and the "dry-mix" process. They dry mix process is more successful and generally used.

\section{References:-}

1. Ayman M, Nour Afify , (1964), "New approaches for rehabilitation and conservation of urbanHeritage", Proceedings of $14^{\text {th }}$ paper of Center of Planning and Architectural studies, EgyptVol. 20, pp. 1-12.

2. Chandar S.S., (2014), "Rehabilitation of Buildings", International Journal of Civil Engineering Research, Vol. 5, No. 4, pp. 333-338.

3. Mulani Heena R., Prof Kumthekar M. B, (2015), "Special Materials for Rehabilitation ofMonuments", International Journal of Engineering Research and Technology, Vol. 4, No. 04,pp. 264-267.

4. Paulo B. Lourenço, (2006), "Structural Restoration of Monuments: Recommendations andAdvances in Research and Practice", Proceedings of 1st International Conference onRestoration of Heritage Masonry Structures, Egypt. pp 1-16

5. Penelis G.R, (1996), "Techniques and materials for structural restoration", Proceedings ofEleventh world Conference on Earthquake Engineering, Greece, Paper No.2089.

6. RalucaPlesu, George Taranu, Daniel Covatariu, (2011) "Strengthening and rehabilitationConventional Methods for masonry structures", Gheorghe Asachi, Technical University oflaşi, Faculty of Civil Engineering and Building Services, Vol. 4, pp 166-176.

7. Rehman Abdul, (2011), "Conservation of Historic Monuments in Lahore: Lessons fromSuccesses and Failures", Pakistan Engineering and Application Science, Vol. 8, pp. 61-69. 